\title{
Içctimai Gelenekler Açısından Selçuklularda Toy, Düğün Törenleri ve Gelenekleri (Sultan Alp Arslan Dönemi)
}

\author{
Aziz Bașdin ${ }^{1}$
}

\section{Özet}

Türk tarihinde ve Türk devlet nizamında önemli bir yeri olan gelenekler ve törenler, binlerce yıllık bir maziye sahip olan Türk tarihini, çeşitli evreler geçirse de devam eden bir tarihi kültürün parçası olduğunu göstermesi açısından kayda değerdir. Nitekim, dünya üzerinde var olmuş ve var olan toplumlar birbirlerinden kültürel farkları ile ayrılırlar. Bu kültürel farklar gelenekler ve törenler içinde de kendini göstermektedir. Nitekim gelenek ve törenler toplum hayatını düzenleyen değerler bütünü olduğu için cemiyet içinde de birtakım gelenek ve törenler ortaya çıkmışıı. Bunlardan ilki hükümdar ve halkın kaynaşmasını sağlayan, aynı zamanda hükümdarın halkı doyurma vazifesi olarak gördüğü toy törenleridir. Bunun dışında evlenme gelenekleri ve törenleri yer alır. Evlenme gelenekleri içinde kalın, evlenecek erkeğin kız ailesine verdiği teminattır ki İslamiyet'in kabulünden sonra mehir geleneği veya hukuku ile iç içe uygulanmıştır. Ayrıca eski bir gelenek olan saçı geleneği de hem İslamiyet öncesi hem de İslamiyet sonrası Türk sosyal hayatı içerisinde uygulanan düğün gelenekleri arasındadır. Bu çalışmada Sultan Alp Arslan dönemi temelinde Selçuklularda toy, düğün törenleri ve geleneklerinin sosyal açıdan Selçuklu kültürünün bir parçası olduğu açıklanmaya çalışılacaktır.

Anahtar Kelimeler: Toy, Düğün, Tören, Gelenek

\section{"Toy" Wedding Ceremonies And Traditions In Seljuks In Terms Of Social Traditions (Sultan Alp Arslan Period)}

\begin{abstract}
Traditions and ceremonies, which have an important place in Turkish history and Turkish state, are worthy of showing that Turkish history, which has a thousand years of history, shows that it is a part of historical cultures that continue to pass through various stages. Indeed, societies that exist and exist on the earth are separated from each other by cultural differences. These cultural differences also manifest themselves in traditions and ceremonies. As a matter of fact, traditions and ceremonies constitute a whole set of values that regulate the life of society, so that there are also some traditions and ceremonies in the society. These are "toy" ceremonies that make the ruler and the people come together and at the same time the ruler regards the people as a duty to feed. Apart from that, marriage traditions and ceremonies take place. Staying in the tradition of marriage is the guarantee that the man to be married gives to the girl's family that after the acceptance of Islam, it has been applied inside with tradition or law. In addition, the tradition of hair, which is an old tradition, is one of the wedding traditions applied both in pre-Islamic period and post-Islamic Turkish social life. In this study, it will be tried to explain that in the Seljuks, on the basis of the Sultan Alp Arslan period, toys, wedding ceremonies and traditions are part of the Seljuk culture in social terms.
\end{abstract}

Key Words: Toy, Wedding, Ceremony, Tradition

${ }^{1}$ Doktora Öğrencisi, Gazi Üniversitesi, Sosyal Bilimler Enstitüsü, Ortaçağ Tarihi ABD, azizbasdin@gmail.com

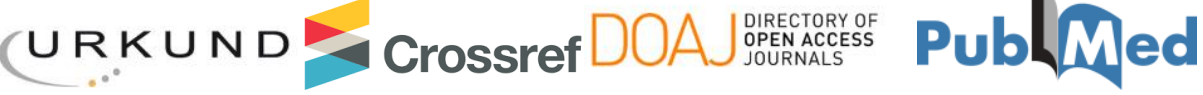




\section{Giriş}

Türk gelenekleri ve törenleri, tarihi gelişmelerin ve değişmenin içinde temelleri ve özü daima korunan bir değerler bütününün var olduğunu bizlere göstermektedir. Türk kültüründe geleneklerin ve törenlerin var olması, Türk kültürünün zenginliğini ve Türklerin kültürüne bağlı bir millet olduğu gerçeğini yansıtmaktadır. Hiç şüphesiz bu kültürün içinde oluşan sosyal gelenekler ve törenler bu kültürün vazgeçilmez bir parçasıdır.

Türk milleti tarihi süreçte birçok coğrafyada hüküm sürmüş, gelenekleri ve törenleri hüküm sürdüğü bu coğrafyalarda şekillenmiştir. İslam dinine girdikten sonra dahi İslamiyet öncesi gelenek ve törenlerini bazı değişimler geçirse de devam ettirmişlerdir. Birçoğu "atlı göçebe kültür" izlerini taşıyan gelenek ve törenleri günümüze değin devam etmiştir. İslamiyet'in kabulü ile bu gelenekler ve törenlerde değişiklikler olsa da aynı geleneğin devamı şeklinde uygulanmıştır. Türk devlet gelenek ve törenleri, Türk töresinde her şeyin üzerinde tutulan devletin kuruluşundan yıkılışına kadar sürmüştür. Milli değerlerine sahip çıkan Türk milleti, töresinin bozulmaması için gelenek ve törenlerini her daim muhafaza etmeye çalışmıştır. Bu içtimai gelenekleri toy töreni, düğün törenleri ve düğüne ait gelenekler ve törenler olarak sıralamak mümkündür.

\subsection{Toy Töreni}

İslamiyet öncesi Türk kağanlarının tek başına karar almamaları için, siyasi, askeri, ekonomik, sosyal ve kültürel meselelerin görüşüldüğü meclis olarak karşımıza çıkan toyun "kengeş", "ternek" ve "kurultay" gibi anlamları vardı (Koca 2010:89). Hükümdarlık alameti olarak da görülen toy, içerik açısından devlet ve saray törenleri için de alınsa da, halkın kaynaşması ve birlik beraberliğin sağlanması için yapılan sosyal törenler olarak da değerlendirmek mümkündür. Başlangıçta dini tören, bayram, yeme içme toyu, eğlence ve yarışmalarında içinde olduğu düşünüldüğünde, zamanla halkında içinde olduğu toplumsal törenler olarak varlığını sürdürdü- ğü açıktır (Erdoğan 2014:42). Zira toy, başlangıçta Türk devlet başkanlarının iktidar ve yönetimi tek olarak yürütebilmek için icat ederek icra ettikleri bir gelenek ve tören olmuş, böylece her dönemde Türk devlet anlayışı içinde iktidar ve meşru hükümranlık alametlerinden biri sayılmıştır. Daha önce zikrettiğimiz gibi daha sonraki dönem içinde Türk hükümdarları toyu içtimai anlamda daha çok öne çıkan bir âdet haline getirmiştir. Örneğin; çocuk isteme, hükümdar çocuklarının doğumu, veliaht tayini, tahta çıkma, bey çocuklarının ilk avlarından dönüşü, akınların ve seferlerin zaferle sonuçlanması, kahramanlık gösterenlere ad verme, esirlikten kurtulma, evlenme ve bayram gibi vesilelerle toy törenleri düzenlenmiştir (Koca 2012:2702).

Oğuzlarda kurultay veya danışma toplantısı yaygın olarak toy veya düğün dernek şeklinde yapılırdı. Yani bu toplantının içinde yemek içmek de vardı. Zaten gerek halkı ve gerekse beyleri yedirmek içirmek, hakanın bir vazifesi idi. Bu toyların içinde, hanın evini yağma etmek de vardı (Ögel 2016:100). Açı doyurma, çıplağı giydirmek Türklerde Göktürk Yazıtlarından Dede Korkuta'a, hatta Manas Destanı'na Selçuk ve Osmanlı topluluklarına kadar, atasözü halinde değișmez bir düstur, bir kanun ve en başta vazife olarak, günümüze kadar devam edegelmiştir. Türklerin İslamiyet'i kabul etmelerinden sonra da İslamiyet'in yüce prensipleriyle çok kolay ve çabuk uyuşmuştur (Ögel 2016:152). Zira İslamiyet'i kabul eden Türk devletlerinde bu gelenek en kâmil şekilde uygulanmıştır. Örneğin; toy verme geleneği ve töreni, Tolunoğulları, Karahanlılar, Anadolu Selçukluları, Atabeylikler, Anadolu beylikleri, Memlukler, Akkoyunlular, Karakoyunlular, Osmanlılar ve Özbekler (Şeybânîler) tarafından uygulanmıştır. Kaşgarlı Mahmud'a göre Türk beyleri bayramlarda ve dügüülerde minareler gibi sofralar kurduruyor, halkı yedirip içirdikten sonra sofra takımlarını yağmalatıyordu (Koca 2012).

Büyük Selçuklu dönemine baktığımızda bu geleneğin pek tabi olarak uygulandığını görmekteyiz. Yağma yapılan bu toylara 11. yüzyılda "kençliyü" denilmekteydi. Nizâmülmülk'e göre Karahanlı hükümdarları gibi 
Büyük Selçuklu Sultanı Tuğrul Bey de ordusuyla gezintiye ve ava çıtığı zaman muhteşem sofralar kurdururdu. Toya katılanlar bu sofraların büyüklüğü ve zenginliği karşısında hayretler içinde kalmaktaydı(Koca,2012). Sultanlar cömert olmak zorundaydı; aksi takdirde devlet liderliği görevine ve millî hukuka karşı çıkmış sayılır ve halkın isyanına maruz kalırdı².

Selçuklu tarihinde çeşitli sebeplerle toy törenleri tertip edilmiștir. Tuğrul Bey, Abbâsî halifesinin kızıyla evlenmesi sebebiyle büyük bir toy vermiştir. Toydan hemen sonra Sultanın sofra takımı düğün töreni ve yemeğe katılan halk tarafından yağma edilmiştir. Bundan başka Tuğrul Bey her sabah sofrasını açık bulundurur, sahralarda da toy verirdi (Koca 2012).

Yine Sultan Tuğrul, kazandığı zafer sonucunda da toy vermiştir. 1060 yılında, Büveyhi komutanı Arslan Besasiri'yi Vasıt mevkiinde yenilgiye uğrattıktan sonra, sarayında büyük bir davet vererek devlet erkanı ve halkı ağırlamıştır (Çaycı 2008:296). Sultan Alp Arslan'ın toy verdiğine dair bilgiler mevcut değilse de ondan sonra gelen Selçuklu sultanlarının toy verdikleri biliniyor olmasından yola çıkılarak Sultan Alp Arslan'ın da toy vermesi kuvvetle muhtemel olduğunu söylemek mümkündür. Zira gelenekler ve törenler hükümdarın da üzerinde görüldüğü için, bunun Sultan Alp Arslan tarafından da uygulandığı tabiidir. Bu gelenek ve tören, Sultan Muhammed Tapar tarafından da icra edilmiştir. Sultan Muhammed Tapar, 1118 tarihinde oğlunu tahta çıkardığı için geniş kitlelere sofra düzerek yemek ikram etmiştir (Çaycı 2008: 297).

\subsection{Düğün Töreni}

Her kültürde olduğu gibi Türk kültüründe de aile, toplumun çekirdeğini oluşturmaktadır. Türk sosyal hayatı akrabalık bağları üzerinde kurulmuştur. Aile, kültürel değerlerin gelecek kuşaklara aktarılmasında köprü vazifesi

\footnotetext{
${ }^{2}$ Büyük Selçuklu Sultanı Melikşah, gittikçe Türk kabile an'anelerinden uzaklaşmış ve İslam hükümdarı gibi hareket etmeye başlamıştı. Nitekim, Melikşah Semerkand ve Özkend seferinde halka ziyafet
}

görmektedir. Bu açıdan bakıldığında aile, toplumun yetiștirilmesinde ve toplum düzenin sağlanmasında birincil vazifeli kurumdur. Ailenin oluşması için evlilik müessesi ortaya çıkmış, zamanla bu da birtakım geleneklerin ve törenlerin ortaya çıkmasına zemin hazırlamıştır.

İslamiyet öncesi Türk kültüründe ortaya çıkan bu gelenek ve törenler İslamiyet ile birlikte de devam etmiş, bugün dahi uygulanan geleneklerin ve törenlerin temelini oluşturmuştur. Eski Türk toplumunda evlenmek, erkek ve kadın açısından bakıldığında aynı manalara gelen faklı kelimelerle ifade edilmekteydi. Erkek açısından "kavuşmak" veya "evlik almak" deyimi, kadın açısından da "erlenmek" kelimesi evliliğin ifade edildiği kelimelerdir (Koca 2010:122). İslamiyet öncesi Türk sosyal anlayışında ailenin meydana gelmesi için evliliğin olması şarttı. Türk anlayışına göre evlenmek veya yuva kurmak Türk devletlerinin temeli sayılmış, bu açıdan bekarlık ayıp sayılmıştır (Mandaloğlu 2008:137-8).

Bu açıdan bakıldığında aile ve dolayısıyla evlilik, Türk kültürü için çok önem arz eden bir konumda olmuş, evlilik olayı birtakım usuller çerçevesinde gerçekleşerek belirli bir sürecin de doğmasına ve akabinde düğün töreninin çıkmasını sağlamıştır. Evlilik öncesi süreç, İslamiyet öncesi Türk kültüründe nasıl devam etmişse İslami devir ve Selçuklu Türk kültüründe de farklı kelimelerle ifade edilse de aynı şekilde devam etmiş ve uygulanmıştır. Örneğin; Eski Türk toplumunda bir gencin evlenme isteğinin ortaya çıkmasıyla, "arkucçı" veya "savcı" adı verilen aracılar devreye girmekteydi (Koca 2010:123). Selçuklu toplumunda da aynı uygulama tatbik edilmiştir. Selçuklularda da görücü usulü ile evlenme geleneği uygulanmış, evlenmek isteyen kadın ve erkek için uygun eş arayışına gidilerek evlenme sağlanmaya çalışılmıştır. Selçuklu toplumunda kız istemek için giden ve evlilik için aracı olan görücülere "savcı

vermediği için bu durum Maveraünnehir halkının ve özellikle Çiğiller'in şikayetlerine sebep olmuştur. Bkz: Turan, 2015: 101. 
arkuçi”, aileler arasında gidip gelen kişiye de "yarıgçı" denirdi (Genç 1975:299).

Evlenme öncesi hazırlıklar tamamlandıktan sonra evlilik için düğün töreni uygulanırdı. Türkler için düğün, yeni bir ev açmakla birlikte nesebin devamı manasına geldiği için aile açısından önemli bir görevin yerine getirilmesini ifade ederdi. Ailenin oluşumunda ilk merhale olarak da görüldüğünden eğlence kültürünün yanı sıra sosyal bir gelenek ve tören olarak karşımıza çıkan düğün törenleri sırasında halk için önemli uygulamalarda görülmüştür (Berber 2009:3). Bu uygulamalar eski Türk toplumundan Selçuklulara ve günümüze değin uygulanmıştır. Selçuklu kültür hayatında halk arasında yapılan düğün törenleri hakkında malumat olmasa da hanedan için yapılan düğün törenlerinden Selçuklu düğün törenleri hakkında bilgi edinmek mümkündür.

Selçuklu düğün törenlerinin temel amacı, düğüne katılan halkı eğlendirmek ve onlara verilen yemeklerle devlete olan güveni sağlamakla birlikte devletin gücünü de göstererek toplumsal kaynaşmayı sağlamaktı. Bunun için “küden” adı verilen düğün yemeği verilirdi. Küden'in işlevine baktığımızda toy ile benzerlik gösterdiği aşikardır. Başka bir deyişle eski bir geleneğin farklı isimle Selçuklularda tezahüründen başka bir şey değildir. Düğün törenlerine katılanlara yemek verilmesi düğün törenlerinin olmazsa olmazıydı. Çünkü verilen yemek, hükümdarın asli vazifesi olan açı doyurma prensibi açısından, birlik ve beraberlik için bir mesaj niteliğindeydi (Berber 2009:8).

Konumuz gereği Selçuklu ve Sultan Alp Arslan dönemine ait düğün törenleri hakkında malumat vermek yerinde olacaktır. Tuğrul Bey'in Halife'nin kızı Seyyide ile olan düğün töreni ve Sultan Alp Arslan'ın eşi Seferiyye Hatun'dan olan kızı ile Emir Uddetüddin'in Nişabur'da kıyılan nikahlarının ardından yapılan düğün törenine baktığımızda Selçuklu düğün törenlerinin geneline ait fikir edinmek mümkündür. Zira halifenin kızı Seyyide ile Tuğrul Bey'in nikahlanmasından sonraki düğün töreninde davullar vurularak borular çalınmıştır. Ayrıca Sultan, hacipler ve Selçuklu ileri gelenleri, sevinç ve mutluluktan dolayı
Darü'l Memleke'nin sahanlığında, oyun oynayarak Türkçe şarkılar söylemişlerdir(ibn'ül Cevzi 2014: 81). Alp Arslan'ın kızı için yapılan dügün töreninde de davullar vurulup, borular öttürülmüştür. Ayrıca, saray süslenmiş filler, üstü giydirilmiş atlarla dolmuştur. Sultan Alp Arslan, törende saltanat tahtına oturmuştur (ibn'ül Cevzi 2014: 109). Bütün bunlardan anlaşllıyor ki, Selçuklu düğün törenleri bayram havasında geçiyor ve uzun süren eğlenceler düzenleniyordu. Yapılan uygulamalar ve eğlencelere bakıldığında, İslamiyet öncesi Türk kültüründe var olan düğün öncesi uygulamalar ile Selçuklu düğün öncesi icra edilen uygulamaların ve törenlerin benzer olduğu açıkça anlaşılmaktadır.

\subsection{Düğün ve Evlenme Gelenekleri}

\subsection{1. Çeyiz Geleneği}

Türk toplumunun düğün geleneğinde çeyiz; geline aile hayatında gerekli malzemeler olan ev ve mutfak eşyası, işlemeli örtüler, takı ve giysilerdir. Bu eşyalar evlenene kadar sandık içinde saklanırdı. Sandığın kullanım amacı, her gün kullanımda olmayacak değerli malzemelerin muhafaza edilmesidir (Usal Yalçın 2010:160).

Türk kültüründe evlenecek olan oğlan, ailesinin kalın adı altında birtakım hediyeler verilmesine karşılık olarak kız ailesi de çeyiz hazırlamak mecburiyetindeydi. Çeyiz bir manada ailenin reisi olan baba mirasından kızın payına düşen mal idi. Eski Türk toplumunda, evlenecek kızın çeyizinin hazırlanması sadece kızın anne ve babasına düşen bir vazife değildi. Çeyiz hazırlama faaliyetini kendilerine vazife olarak gören bütün akraba fertleri gönüllü olarak çeyiz hazırlama işine girişirlerdi (Koca 2010:124).

Eski Türklerden günümüze değin gelen bu gelenek Türk-isslam devleti olan Selçuklularda da uygulanmıştır. Örneğin; Sultan Tuğrul Bey, Arslan Besasiri baskısı sebebiyle Bağdat'a geldiği zaman çevre hükümdarlarının da şeref duyup memnun kalacağı bir akrabalık ilişkisi kurmak amaciyla Halifelik kurumuyla akrabalık kurmak istiyordu. En nihayetinde bu konu hakkında anlaşmaya varılarak halifenin 
oğlu Zahiretüddin ile Çağrı Bey'in kızı Arslan Hatun'un evlenmesine karar verilerek söz kesildi. Ancak bir süre sonra halifenin oğlu vefat edince, bu kez, sözün halife ile Arslan Hatun arasında olması gündeme gelmiştir. Bunun için halifenin isteğini kapsayan birkaç mektup Sultana gönderildi. Halifenin bu isteği Sultan tarafından kabul edilmiştir. Bunun üzerine Sultan Tuğrul Bey, Selçuklu emirleriyle birlikte kadılar, şahitler, bilgin ve tacirleri saraya davet etmiş içinde çeyizlerin (çehiz) bulunduğu süslenmiş odaları onlara göstermiștir. Halifenin sarayına nakledilen bir benzeri olmayan çeyizler arasında şunlar vardı: Üzerinde genç kızların bulunduğu yük taşıyan develer, katırlar, para, cevahir, yakutlar, altın ve gümüş kaplar, üzerinde halis ipek kumaştan yapılmış atlar ve Rum katırları olan kız oğlan kız, sekiz cariye, üzerlerinde mücevher işlenmiş kaftanlar bulunan katırların üstünde altı genç kız vs. vardı(Sıbt Ibnü’l Cevzi 2011:15).Bunlardan anlaşılıyor ki eski Türklerden beri var olan çeyiz geleneği Selçuklularda da devam etmiş ve içerik olarak çok değerli eşyaları kapsamıştır.

\subsubsection{Saçı Geleneği}

Türk kültüründe evlenme gelenekleri arasında yer alan faaliyetlerden biri de saçı saçma geleneğidir. Saçı, düğünlerde damat tarafından gelinin başına serpilmesi gelenek haline gelmiş para, buğday, çiçek ve geline verilen hediye, davetlilerin getirdikleri düğün armağanı anlamlarına gelmektedir (Kurtoğlu 2009). İslamiyet öncesi Türk kültüründe var olan bu gelenek Müslüman Türk devletlerinde de uygulanmıştır. Türk-İslam tarihinde saçı geleneğiyle ilgili ilk uygulamalar, Karahanlı ve Oğuz Türklerinde görülmektedir. Karahanlılar "gelin indirme" törenlerinde bugün dahi birçok yerde yapıldığı gibi gelinin attan inip eve gidişi esnasında başına para ve değişik hububat saçarlardı (Kurtoğlu 2009).

Saçı geleneği Selçuklu kültüründe de uygulanmıştır. Selçuklularda Türk adeti gereğince nikahtan sonra büyük bir ziyafet verilir, bunun yanında saçı da saçılırdı (Koca 2016:367). Örneğin; Sultan Tuğrul Bey'in Abbasi halifesinin kızı ile evlenmesi sırasında yapılan düğün töreninde saltanat çadırının ve saltanat tahtının önünde altın ve gümüş paralar saçılmak suretiyle saçı adetini icra etmişlerdir (Koca 2010:124).

Saçı geleneği Sultan Alp Arslan devrinde de uygulanmıştır. Sultan Alp Arslan'ın kızı ile Abbasi veliahdı için yapılan düğün töreninden sonra düğün için toplanan kalabalığa kaseler içinde kıymetli mücevherler ve altın paralar dağıtılmış (Sıbt ibnü'l Cevzi 2011:109), Sultan Alp Arslan da kızının nikahından sonra iki tabak içinde kendi elleri ile saçılar saçmıştır (Köymen 2016:308).

Eski Türk adeti olan saçı, farklı vesilelerle de uygulanmıştır. Selçuklu tahtına yeni bir hükümdar çıkınca, tören sırasında, fetih kutlamaları sonucunda halk tarafından Sultanın üzerine altın ve gümüş paralar saçllarak Türk adeti yerine getirilmiştir (Koca 2016:368).

\subsubsection{Kalın ve Süt Hakkı Bağlamında Mehir Geleneği}

Evlenme geleneklerinde biri de "kalın"dır. Kalın, İslami devir ile birlikte devam etmiş, islam Aile hukukundaki mehir geleneği ile bütünleşmiş ve ayrıca anneye verilen süt hakkını da kapsamıștır. İslamiyet öncesi Türklerde oğlanın ailesi tarafından kız ailesine verilen hediyelere kalın denilmiştir (Koca 2010:123). Hediyenin yanında para veya mal da olabilen kalın, erkek tarafının sosyo-ekonomik durumuna ve dönemin koşullarına göre değișebiliyordu. Kalın; çeyize, annesinin süt hakkına veya ailenin kızı yetiștirilmesine karşılık olarak erkeğin nişanlısını ilk ziyaretinde verilirdi (Ögel 1988:258). Eski Türklerde süt hakkına "yelü" deniyordu. Süt hakkı olan "yelü" gelinin annesinin şahsında kız tarafına para veya mal karşılığı verilebiliyordu (Can 2008:155). Kalın, erkeğin kadını satın alması değil, bugünkü haliyle sadece erkeklik onurunun kadın karşısında garanti altına alınmasıdır ki evlenecek delikanlı kız tarafına "kalın" vermek zorundaydı (Erkul 2002). 
Türklerin İslamiyet'i kabulü ile birlikte her alanda olduğu gibi düğün geleneklerinde de değișmeler olmuştur. Bunlardan biri olan kalın, İslam ile birlikte gelen mehir geleneğine adapta edilerek uygulanmıştır. Sözlük anlamı "sadaka" olan mehir, İslam aile hukukuna göre evlilik esnasında ödenen para veya malı ifade etmektedir. İslam Aile hukukunda kadının hakkı olan mehir, kadının rızası olmadan başka bir yakınına devredilemezdi. Söz konusu ödeme nakit olacağı gibi mal da olabilmekteydi (Gümrükoğlu 2013). Erkek, karısı bağışlamadığı sürece er ya da geç bunu ödemek zorundaydı. Mehir olarak verilen mal, kadının bedeli veya ondan istifade imkanının karşılığı değil, tıpkı kalın gibi bir ömür boyu beraber yaşama arzusunun sembolik bir alametiydi (Acar 2011).

İslamiyet'in kabul edilmesiyle i̇slam hukuku içerisinde olan mehir, Türk kültüründe de var olmuştur. Mehir, İslam hukukunun geçerli olduğu Selçuklularda da uygulanmıştır. Kız isteme olayında, erkek tarafına olumlu cevap verilmesi durumundan sonra sıra mehrin belirlenmesine gelirdi. Mehir peşin veya taksitlerle ödenebiliyordu (Aksoy 1992:563).

Selçuklu sultanı Tuğrul Bey'in Abbasi Halifesinin kızı Seyyide ile nikahının yapılması için de mehir geleneği uygulanmıştır. Nikâh için elçi olan ibnü'l Mahleben, halifeye mektup yazarak, nikâhın kıyılmasının istendiği ve nikâh vekaletinin vezir Amidü'l Mülk'e teslim ettiğini söylemişti. Bu vesileyle 400 bin altın mehir açıklanınca halife yüksek sesle dua etmiş ve nikâh akdi yapılmıştır (Sıbt İbnü'l Cevzi 2011:112). Nikâh akdi yapıldıktan sonra da Tuğrul Bey, düğün amacıyla Bağdat'a gelmesinden sonra, Sultan ve Halife arasında Seyyide'nin Darü'l Memleke'ye gitmesi, Sultanla sefere çıkmaması gibi konularda anlaşma yapılmıştır. Bu anlaşmadan sonra Sultan halifeye mehir karşılığı olarak 100 bin altın, 150 bin dirhem, 4 bin giysi ve 10 soylu yörük atı hediye etmiştir (ibnü'l Cevzi 2014:81). Bundan başka, 13 Mart 1056 Çarşamba günü, Halife el- Kaim Biemrillah'ın, Sultan Tuğrul Bey'in kardeși, Çağrı Bey'in kızı Hatice veya Arslan Hatun ile 100 bin altın mihr karşılığında nikâhları kıyılmıştır. Nikâhta Kadi’l Kudat Ebu Abdullah ed-Damgani, Başkadı Ebu'l Kasım İbnü'l Müslime hazır bulundular.
Bir süre sonra İbnül Müslime, “Efendimiz ve büyüğümüz Emirü’l Mümininin lütfedip nikâhı uygun görüp kabul buyururlarsa nikâhı kıyarım" dedi. Bunun üzerine Halife "Bu nikâhı bu mihr ile kabul ettik" dedi (Ibnü'l Cevzi 2014:27).

\section{Sonuç}

Birçoğu Eski Türk devlet hayatı içerisinde var olan, diğerleri de İslamiyet'in kabulüyle ortaya çıkan Selçuklu içtimai gelenekleri ve törenleri, Sultan Alp Arslan döneminde de tatbik edilmiștir. Sultan Alp Arslan döneminde uygulanan içtimai gelenekler ve törenler birçok yönden eski Türk kültürünün birer yansıması olmuştur.

Türk milletinin tarih sahnesine çıkışından Selçuklulara değer verilen en önemli hususlardan biri de toplumsal kaynaşma ve dayanışma olmuştur. Bunu gerçekleştirmek için içtimai hayatta birtakım gelenek ve tören sayılabilecek uygulamalar ortaya çıkmıştır. Hiç şüphesiz toy töreni, düğün töreni ve sonrasında yapılan uygulamalar toplum içinde birlik ve beraberliği sağlama da çok önemli bir fonksiyona sahip olmuşlardır. Ayrıca içtimai hayattaki bu uygulamalar hem toplum kaynaşmasını hem de Türk milletinin idare kabiliyetini ortaya çıkarmada etkili oluşlardır. Bütün bu gelenek ve törenler milletini ayakta tutmaya çalışan Selçuklu sultanı Alp Arslan döneminde de uygulanmıştır. Bunun yanında bu gelenekler ve törenler Türk milletinin varlığını korumasını ve sürekli olmasını sağlamış, devletler ve hanedanlar yıkılsa da gelenek ve tören anlayışı değişmemiş, her devirde uygulanmaya gayret gösterilmiştir. 
Kaynakça

Acar, H.ibrahim. (2011). Mehrin İslam Hukuku Açısından Değerlendirilmesi. i̇slam Hukuku Araştırma Dergisi, (17), 367-388.

Aksoy, Hasan. (1997). Tarihi Bir Belge ve Türk İslam Edebiyatında Bir Tür Olarak Fetihnameler. Ilam Araştırma Dergisi, 2(2), 7-19.

Berber, Oktay. (2009). Türk Kültüründe Eğlence ve Birlik Unsuru Olarak Düğünler. Süleyman Demirel Üniversitesi Sosyal Bilimler Dergisi, 2(10), 1-11.

Can, Sevim. (2008). Selçuklular Döneminde Kadın. (ikinci Baskı). İstanbul: Ufukötesi Yayınları.

Çaycı, A. (2008). Selçuklularda Hükümdarlık Sembolleri. (Birinci Baskı). İstanbul: izz Yayıncilık.

Erdoğan, A. (2014). İslamiyet'ten Önce Türk Devletlerinde Meclis Anlayışı: Toy, Kengeş, Kurultay örneği. Kahramanmaraş Sütçü İmam Üniversitesi Sosyal Bilimler Dergisi, 11(2), 39-52.

Erkul, Ali. (2002). Eski Türklerde Evlenme Gelenekleri. Türkler Ansiklopedisi. Cilt 3. Ankara: Yeni Türkiye Yayınları, 58-66.

Genç, R. (1975). XI. yüzyılda Türklerde Evlenme. Ankara Üniversitesi Dil Tarih Coğrafya Fakültesi Antropoloji Dergisi, (7), 299.

Gümrükoğlu, Saliha,Okur. (2013). İslam Aile Hukukunda Kadının Mehir Hakkına Toplumun Bakış Açısı Üzerine Bir Değerlendirme. GÜ Hukuk Fakültesi Dergisi, 17(4), 223-256.

ibnü'l Cevzi. (2014). El Muntazam fi Tarihi'l Ümem'de Selçuklular. (Çev. A. Sevim). Ankara: TTK Yayınları.
Kafesoğlu, ibrahim. (2014). Sultan Melikşah Devrinde Büyük Selçuklu Imparatorluğu. (ikinci Baskı). İstanbul: Ötüken Yayınları.

Koca, Salim. (2010). Türk Kültürünün Temelleri-Il. (Üçüncü Baskı). Ankara: Kültür Yayınları.

Koca, Salim. (2012). Toy. Türkiye Diyanet Vakfı (TDV) İslam Ansiklopedisi. cilt: 41,270272

Koca, Salim. (2016). Türkiye Selçukluları Tarihi: Sultan Alp Arslan'dan Uluğ Keykubad'a (1071-1220). (Birinci Baskı). Ankara: Berikan Yayınevi

Köymen, Mehmet, Altay. (2016). Büyük Selçuklu Imparatorluğu Tarihi, III. Cilt, Alp Arslan ve Zamanı. (Altıncı Basım). Ankara: TTK Yayınları

Kurtoğlu, Orhan. (2009). Klasik Türk Şiirinde Saçı Geleneği. Milli Folklor Dergisi, 21(8), 89-99.

Mandaloğlu, Mehmet. (2013). İslamiyet'ten Önce Türklerde Aile Hukuku. Türkiyat Araştırmaları Dergisi, 1(13), 133-159.

Ögel, Bahaeddin. (1988). Dünden Bugüne Türk Kültürünün Gelişme Çağları. (Birinci Baskı). İstanbul: Türk Dünyası Araştırmaları Vakfı, 258.

Ögel, Bahaeddin. (2016). Türklerde Devlet Anlayışı. (ikinci Basım). İstanbul: Ötüken Yayınları.

Sıbt ibnü'l Cevzi, (2011). Mir'atü'z-Zaman Fi Tarihi'l-Ayan'da Selçuklular. (Çev. Ali Sevim, Ankara: TTK Yayınları.

Turan, Osman. (2016). Selçuklular Zamanında Türkiye. (Ondördüncü Basım). İstanbul: Ötüken Yayınları.

Usal Yalçın, S. Selhan. (2010). Türklerde Çeyiz Sandığının Kullanımı ve Geleneksel Süslemeleri. Ordu Üniversitesi Sosyal Bilim Enstitüsü Sosyal Bilimler Araştırma Dergisi, 1(1), 157-167. 